\title{
I 02 I Relation between the assessment of microvascular injury by cardiovascular magnetic resonance and coronary Doppler flow velocity measurements in patients with acute anterior wall myocardial infarction
} Robin Nijveldt*1, Alexander Hirsch ${ }^{2}$, Aernout M Beek ${ }^{1}$, Joost DE Haeck ${ }^{2}$, Karel T Koch², Jose PS Henriques ${ }^{2}$, Rene van der J Schaaf ${ }^{2}$, Marije M Vis ${ }^{2}$, Jan Baan ${ }^{2}$, Robbert J de Winter ${ }^{2}$, Jan GP Tijssen ${ }^{2}$, Albert C van Rossum ${ }^{1}$ and Jan J Piek ${ }^{2}$

Address: ${ }^{1}$ VU University Medical Center, Amsterdam, The Netherlands and ${ }^{2}$ Academic Medical Center, Amsterdam, The Netherlands * Corresponding author

from I th Annual SCMR Scientific Sessions Los Angeles, CA, USA. I-3 February 2008

Published: 22 October 2008

Journal of Cardiovascular Magnetic Resonance 2008, I0(Suppl I):AI46 doi:I0.I I86/I532-429X-I0-SI-AI 46

This abstract is available from: http://jcmr-online.com/content/I0/SI/AI46

(c) 2008 Nijveldt et al; licensee BioMed Central Ltd.

\section{Introduction}

Cardiovascular magnetic resonance (CMR) has been used to detect and quantify microvascular obstruction (MVO) in patients after acute myocardial infarction but has never been compared to coronary blood flow velocity patterns.

\section{Purpose}

We studied the relation between the presence and severity of MVO measured by CMR and intracoronary Doppler flow measurements, for assessment of myocardial reperfusion in patients with acute anterior wall myocardial infarction treated by primary percutaneous coronary intervention (PCI).

\section{Methods}

Twenty-seven patients with first anterior ST-elevation myocardial infarction successfully treated with primary PCI were prospectively enrolled. Using a Doppler guidewire, coronary blood flow velocity was measured during re-catheterization 4-8 days after primary PCI. These measurements were related to MVO determined by late gadolinium-enhanced (LGE) CMR performed the day before re-catheterization.

\section{Results}

Early systolic retrograde flow was observed in 0 of 8 patients without MVO on LGE CMR and in $10(53 \%)$ of 19 patients with MVO $(\mathrm{p}=0.01)$. The extent of MVO correlated with diastolic-systolic velocity ratio $(\mathrm{r}=0.44, \mathrm{p}=$ $0.02)$, diastolic deceleration time $(\mathrm{r}=-0.61, \mathrm{p}=0.001)$, diastolic deceleration rate $(\mathrm{r}=0.75, \mathrm{p}<0.0001)$, and coronary flow velocity reserve of the infarct-related artery $(\mathrm{r}=$ $-0.44, \mathrm{p}=0.02)$. Furthermore, multivariate regression analyses including the extent of MVO, infarct size, and transmural necrosis on LGE CMR, revealed that the extent of MVO was the only independent factor related to early systolic retrograde flow and diastolic deceleration rate.

\section{Conclusion}

Assessment of microvascular injury by LGE CMR corresponds well to evaluation by intracoronary Doppler measurements. By means of CMR, quantification of myocardial function, infarct size and microvascular injury can accurately be performed with a single non-invasive technique in patients with an acute myocardial infarction.

Assessment of microvascular injury by LGE CMR corresponds well to evaluation by intracoronary Doppler 
measurements, and can accurately be performed with a single non-invasive technique in patients after an acute myocardial infarction.

Publish with Bio Med Central and every scientist can read your work free of charge

"BioMed Central will be the most significant development for disseminating the results of biomedical research in our lifetime. " Sir Paul Nurse, Cancer Research UK

Your research papers will be:

- available free of charge to the entire biomedical community

- peer reviewed and published immediately upon acceptance

- cited in PubMed and archived on PubMed Central

- yours - you keep the copyright 